\title{
A TRANSIÇÃO DA ESCOLA PARA O MUNDO DO TRABALHO CONSTITUIIDA EM OBJECTO DE ESTUDO:
}

\author{
Uma abordagem teórico-metodológica
}

Maria Sidalina Almeida*

RESUMO: A transição da escola para o mundo do trabalho está marcada por uma crescente complexidade que exige uma aproximação teórico-metodológica capaz de realçar a sua análise em termos de processo. A transiçấo é abordada como um período de socialização e de construção identitária. Esta resulta, em simultâneo, da transação biográfica, que é a construção de uma identidade "para si", contemplando o tempo passado, as experiências vividas do tempo da transição e a projeção do futuro possível; e da transação relacional, através da qual o jovem constrói um posicionamento de si por relação ao outro. Análises biográficas e longitudinais são enfatizadas, pois a transição é um período no qual os jovens (re)escrevem continuamente seus percursos educacionais e profissionais que se entrecruzam na sucessão do tempo. Este artigo propóe os questionários longitudinais para o estudo das trajectórias objectivas e valoriza as entrevistas biográficas para o estudo das trajectórias subjectivas.

Palavras-chave: Transição da escola para o mundo do trabalho. Construção identitária. Trajectórias objectivas e subjectivas.

* Instituto Superior de Serviço Social do Porto, Portugal. 


\section{The transition from school to the labor world constituted into an object of study: a theoretical-methodological approach}

ABSTRACT: The transition from school into the labor world is marked by an increasing complexity that requires a theoretical-methodological approach capable of highlighting its analysis in terms of process. The transition is emphasized as a period of socialization and identity construction. This results, simultaneously, from the youths biographical transaction, which is the construction of an identity "for themselves" that involves the past, the experiences lived during the transition time and the projection of the possible future; and from the relational transaction, through which a young person constructs a positioning of the self in relation to the other. Biographical and longitudinal analysis are advocated in this paper, since the transition is a period in which young people continually (re)write their educational and professional paths which interconnect in time progression. This paper proposes longitudinal surveys for the study of objective trajectories and values the biographical interviews for the study of subjective trajectories.

Keywords: Transition from school into the labor world. Identity construction. Objective and subjective trajectories.

\section{O FENÓMENO SOCIAL DA PASSAGEM DO SISTEMA DE EDUCAÇÃO PROFISSIONAL PARA O SISTEMA DE EMPREGO}

A defasagem no tempo entre a conclusão de um nível de escolaridade e a obtenção de um emprego, intensificado desde finais dos anos setenta do século XX, leva os jovens a entrar num longo e complexo processo de transição, no qual não é fácil identificar o seu início e fim (ALVES, 2007; CHARLOT; GLASMAN, 1998; DUBAR, 1998). Mais do que o modelo instantâneo de transição entre conhecidos e seguros estágios, destacam-se a não linearização e a não sincronização dos ritmos das suas passagens, reveladas pelo desajustamento geral dos três processos que tradicionalmente estavam associados 
na passagem à vida adulta: "o fim dos estudos, o acesso ao emprego e a constituição da nova família” (GALLAND, 1997, p. 55).

A transição hoje caracteriza-se pela reversibilidade e transitoriedade das situaçóes, dos papéis e estatutos, havendo passagens diversas entre "escola-formação-trabalho", uma alternância entre situações de trabalho, procura de emprego, duplo emprego, ocupação de postos contratuais sucessivos entrecruzados com períodos de espera, situaçóes de ocupação ocasional, desemprego e retorno aos estudos. $\mathrm{O}$ movimento e a descontinuidade da transição e a grande diversidade nas formas das passagens são elucidados pelas expressóes "labirintos de vida" e "trajectórias não-lineares, caracterizadas pelo movimento yô-yô" presentes no curso de vida de muitos jovens (PAIS, 2001, p. 9).

A transição da escola ao mundo do trabalho e o próprio processo de inserção profissional dos jovens transformou-se numa fase intermédia, num tempo de moratória, "num verdadeiro percurso do combatente” (CHARLOT; GLASSMAN, 1998, p. 21). É um dos principais problemas com que se debate a juventude contemporânea, sendo eleito para a intervenção pelos poderes públicos através de medidas de política de educação e formação profissional, de emprego e de juventude. Trata-se de um período de "crise do emprego" e de "crise da escola”, em que o Estado, através dos dispositivos públicos de inserção que se ocupam com a "gestáo das longas passagens", assume centralidade e contribui para a verdadeira institucionalização da juventude (DRANCOURT; BERGER, 1995, p. 30).

\section{OS CONCEITOS DE "INSERÇÃO PROFISSIONAL", "ENTRADA NA VIDA ADULTA" E "TRANSIÇÃO DA ESCOLA PARA O TRABALHO": A CONSTRUÇÃO DO OBJECTO DE ESTUDO}

Nas últimas décadas, o processo de transição para a vida activa e as questóes da juventude na sua globalidade constituíram-se num objecto de crescente interesse científico nas diversas áreas das ciências sociais. Contudo, este campo de investigação continua fluído teórica e metodologicamente porque a maioria dos estudos foi encomendada 
pelos poderes políticos e serviu para a elaboração de políticas públicas de combate a estes problemas sociais, usando-se categorias sem definição teórica. Acresce referir que se trata de um campo de investigação com uma diversidade de conceitos usados em diferentes períodos da história recente, precisando ser enquadrados nas características socioeconómicas das sociedades onde surgiram e nas correntes teóricas a que se afiliam.

A inserção profissional remete a noções fluídas e polissémicas, temporalmente situadas e socialmente construídas (MARQUES; ALVES, 2010). Como refere Alves (2007), o fenómeno social da passagem do sistema de educação/formação profissional para o sistema de emprego tem sido denominado de formas diversas: "entrada na vida activa", "inserção profissional”, "entrada no emprego" e "entrada no trabalho", "transição para o trabalho", "transição profissional”, "transição da escola para o trabalho", "entrada na vida adulta” etc.

A evolução observada no uso desses conceitos - em que "entrada na vida activa”, em França, foi substituída por "inserção profissional” e "entrada no trabalho", em Inglaterra, foi substituída por "transição para o trabalho" (ALVES, 2007) - considera a inserção profissional/ transição ao trabalho como processo que deve ser contextualizado (VERNIÈRES, 1997; GALLAND, 1985; ROSE, 1996), sendo uma construção pessoal e social (VINCENS, 1997; TROTTIER et al., 1998; DRANCOURT; BERGER, 1995; DUBAR, 1998).

A inserção profissional ou a transição ao trabalho envolve um conjunto articulado de processos dinâmicos que questionam a noção de inserção como movimento sequencial entre a educação e o trabalho, bem como a própria noção de inserção.

Procurando demarcar-se das abordagens baseadas em pesquisas quantitativas limitadas à recolha de factos, Vincens $(1981,1997)$ elaborou o primeiro esforço para delimitar o conceito de inserção profissional, entendido como processo individual, que implica a realizaçáo do projecto profissional e de vida do indivíduo que o protagoniza. Concebeu a inserção profissional como uma mudança de estado, uma sucessão de acontecimentos individuais objectiva e subjectivamente vividos, considerando que no processo de inserção, além dos actos desenvolvidos por diversos agentes económicos, deve considerar-se o indivíduo que "é um 
sujeito activo" (VINCENS, 1981, 1997) com as suas decisóes, acçóes e pontos de vista, isto é, com as suas representaçóes do processo.

Vincens (1981, 1997) aborda a inserção como uma passagem de um estado inicial a um estado final. $\mathrm{O}$ início da inserção é relacionado à mudança na utilização do tempo, quando o indivíduo deixa de o partilhar entre o lazer, os estudos e o trabalho não remunerado, para consagrar algum tempo a um emprego remunerado ou à procura de emprego. Já o final da inserção se dá quando o indivíduo necessitará de cessar a utilização do tempo de procura de emprego e, ao mesmo tempo, considerar ter um emprego durável, no sentido de não dispor de informaçôes que lhe permitam antever que terá de mudar num futuro mais ou menos próximo (VINCENS, 1981).

Num trabalho mais recente, Vincens (1997) defende que o final do período de inserção pode ser identificado recorrendo a definições inscritas em dois pólos: o da exterioridade, centrado no investigador que define os critérios para determinar o fim do processo de inserção de uma coorte, considerando os mesmos acontecimentos para todos os indivíduos; o da interioridade, centrado no indivíduo e no sentido que ele atribui à inserção como estado final de um processo e em que o investigador "pede ao próprio indivíduo para definir o fim da inserção" (VINCENS, 1997, p. 24). Há trabalhos que elegem simultaneamente as definiçôes objectivas e as subjectivas: a partir de critérios objectivos, o investigador escolhe o acontecimento inicial que seria o mesmo para todos, sendo que o acontecimento que marca o fim é encontrado a partir das representaçóes dos jovens (VINCENS, 1997).

Uma das questóes decisivas é determinar o acontecimento que marca o fim do processo. Para isso, utilizar o critério da obtenção de um emprego estável pode ser inadequado, num tempo em que predominam os empregos precários e as novas formas de subemprego (os estágios e as bolsas), os quais deixaram de ser um acontecimento pontual para se constituírem num modo de vida para um número crescente de jovens (ALVES, 2007). Nesse contexto, sobressai a definição de Vernières (1997), segundo a qual o início da inserção profissional é o momento em que a pessoa, pela primeira vez, procura ou realiza uma actividade produtiva, e o fim aquele em que foi alcançada uma "posição estabilizada" no emprego (VERNIÈRES, 1997). Isso não significa necessariamente um 
emprego estável com um contracto a tempo indeterminado, podendo ocupar duravelmente posiçóes instáveis.

Usa-se o termo estabilidade e não "estável" porque o processo de inserção pode concluir-se por uma posição duravelmente instável no sistema de emprego (VERNIĖRES, 1993, 1997). Por essa razão, o autor examina melhor a complexidade do "processo de inserção profissional considerado como socialmente condicionado pelos empregadores e respectivos modos de gestão da mão-de-obra, bem como pela situação do mercado de trabalho e pela área, natureza e nível de formação do indivíduo".

Galland $(1985,1991,1997)$ também analisa a inserção profissional como um processo condicionado pela alteração dos modelos de entrada na vida adulta. Trata as questóes da juventude como um processo que conduz a uma outra idade de vida que é a adultez. Para ele, a inserção profissional é um dos acontecimentos da entrada na vida adulta e está intrinsecamente ligada e condicionada por outros acontecimentos. Durante muito tempo, era possível falar de um modelo em que os diferentes acontecimentos que marcam a vida adulta ocorriam simultaneamente. $\mathrm{Na}$ atualidade, houve mudanças e, para falar da juventude, o autor propóe o modelo de experimentaçáo progressiva. Este é caracterizado por um modo de acesso à vida adulta, em que os acontecimentos não coincidem necessariamente num dado momento temporal. Isso torna cada vez mais difícil procurar um acontecimento que marque o término da juventude e o início da vida adulta.

Galland (1997) considera necessário levar em conta o conceito de "entrada na vida adulta", definido a partir de critérios socialmente significativos, correspondentes a mudanças fundamentais de estatuto: o fim dos estudos; o início da vida profissional; a partida da família de origem; o casamento e a constituiçáo de uma nova família. Sobre dois eixos de passagem, quatro entradas são particularmente significativas, pois elas introduzem os jovens em novos estatutos e papéis sociais que delimitam as fronteiras da idade. Pode distinguir-se o eixo de passagem entre a escola e o mundo do trabalho (esfera pública) e o eixo de passagem entre a família de origem e a fundação de uma nova família (esfera privada). Duas das "entradas" constituem limiares de saída - o fim dos 
estudos, a saída da casa dos pais; as outras duas são limiares de entrada: o início da vida profissional, o casamento/união de facto.

Também Trottier, Laforce e Cloutier (1998) dão importantes contributos para complementar a abordagem de Vincens (1997), segundo o qual a inserção profissional é a realização do projecto de vida do indivíduo. Aqueles autores questionam a noção de inserção profissional num dos seus pontos mais críticos: o do comportamento racional do indivíduo que procura um emprego relacionado ao seu projecto de vida. Sublinham que o processo de inserção profissional é um período complexo de socialização e de construção identitária. Além de fenómenos estruturais (como o desemprego e a precarização do emprego), as dificuldades de inserção podem ter origem na forma mais ou menos clara como cada sujeito define o seu projecto e identidade profissionais. Nem todos os jovens têm estratégias de inserção profissional "deliberadas", há os que têm "estratégias emergentes", ou seja, indivíduos cujas decisóes em matéria de inserção profissional são tomadas em separado, não obedecendo a uma identificação de objectivos de longo prazo, mas em função dos constrangimentos, oportunidades e recursos disponíveis no momento (ALVES, 2003).

Trottier, Laforce e Cloutier (1998) procuram também demarcar o início e o fim do período de inserção. Tal como Vincens (1997), identificam o início do processo com o dedicar tempo à procura de emprego ou a uma actividade remunerada. São as representaçóes de inserção dos jovens que lhes fornecem critérios para delimitar o fim do processo. É um exemplo de aplicação da definição "subjectiva": considerando a estabilidade no mercado de trabalho, um emprego que os jovens não pensam em deixar a curto termo, no qual pretendem fazer carreira e também realizar seu projecto profissional e de vida, que se vai construindo durante o período de inserção e ao longo da vida profissional. A estabilidade, à semelhança de Vernières (1997), não é identificada unicamente ao emprego com contracto de duração indeterminada, mas também pela "empregabilidade", ou seja, as competências desenvolvidas no jovem que lhe permitem manter-se no mercado de trabalho, mesmo ocupando empregos de duração determinada. 
Outro critério adotado por Trottier, Laforce e Cloutier (1998) para identificar o fim do processo é o da correspondência entre a formação desenvolvida e o emprego, que não ocorre automaticamente com a obtenção do diploma. Por último, identificam, nas representações da inserção, o processo de socialização profissional, visto sob o ângulo da construção da identidade profissional. $\mathrm{O}$ tema da entrada no trabalho coloca em relevo a passagem do estatuto de estudante ao de trabalhador e traduz o sentimento que os diplomados têm de terem adquirido capacidade de desempenhar o seu papel profissional e assumir responsabilidades de forma autónoma e confiante. Este tema foi interpretado como manifestação do "processo de construção da identidade por si". (TROTTIER; LAFORCE; CLOUTIER, 1998, p. 334).

Os diplomados querem ser vistos como competentes e desejam que o meio de trabalho lhes atribua as competências e habilidades que eles pensam ter desenvolvido. Trata-se da tomada de consciência do "processo relacional" de construção da identidade, pois náo é suficiente confirmar-se a si-mesmo a sua identidade profissional. No eixo relativo ao processo de socialização profissional é possível situar os diplomados por relação ao pólo que diz respeito ao reconhecimento pelo outro da identidade que eles estimam ter construído (TROTTIER; LAFORCE; CLOUTIER, 1998). A construção da identidade profissional começa na formaçáo, identificando-se com a ocupação antecipada e culmina quando a socialização e a construção de uma identidade profissional e o reconhecimento por outro são efectivos (TROTTIER; LAFORCE; CLOUTIER, 1998).

Dubar (1992, 1994, 2000) e Drancourt e Berger (1995) também abordam a inserção profissional como um processo de socialização e de construçáo identitária que envolve a construçáo do projecto profissional e do projecto de vida pelos jovens. Contudo, sua preocupação é perceber a articulação entre condicionantes estruturais e individuais do processo, "questionando até que ponto a forma como decorrem os processos de inserção profissional é influenciada pelas estratégias de cada indivíduo e pelas condiçóes estruturais da economia e do mercado" (ALVES, 2003, p. 3).

Quando analisa as trajectórias dos jovens, Dubar (1992, 1994, 2000) as considera como expressão de formas identitárias emergentes de 
percursos pós-escolares. Salienta dois pólos que correspondem a duas componentes do processo de construção da identidade profissional. A primeira delas refere-se à "transacção interna" ao indivíduo, que trata da incorporação da identidade a partir das suas experiências escolares e profissionais, através das quais ele chega a uma definição de si próprio, aparecendo como o resultado de um processo biográfico. A segunda diz respeito a uma "transacção externa" entre o indivíduo e as instituiçóes com as quais ele está em interacção, porque a construção da identidade depende também desse processo relacional.

O conjunto das decisões assumidas, espontânea ou forçadamente, contribuem para talhar a identidade de um indivíduo. No momento em que se confronta com o mercado de trabalho - quando as competências lhe são reconhecidas, um estatuto lhe é conferido, as possibilidades de carreira se tornam mais precisas - a sua identidade profissional é confirmada pelo julgamento do outro (DUBAR, 1992, 1994, 2000).

Para Drancourt e Berger (1995), as trajectórias são produto de lógicas objectivas e subjectivas. As lógicas institucionais (instituiçóes e profissionais) contribuem para construir trajectórias individuais; as lógicas individuais designam formas diversificadas, mas coerentes de racionalidade. Numa dinâmica de construção permanente, estas diferentes lógicas colocam em prática o processo de "socialização profissional", no qual o percurso de inserçáo juvenil é uma variante.

O quadro teórico aqui apresentado permite delinear o conceito de transição como o período que decorre entre a conclusão da formação e a obtenção do primeiro emprego. Hoje, se traduz por um processo longo, relativamente autônomo, dos períodos de formação e de emprego. A proposição desse conceito póe em questão a relação harmoniosa entre formação e emprego, que é considerada como um espaço pouco claro, fruto do cruzamento de diferentes disposiçóes e onde se traçam as trajectórias possíveis dos indivíduos. A passagem dos sujeitos de um espaço a outro e a forma como eles vivenciam essa passagem implicam o conceito de transiçáo. Integramos os contributos dos autores que adotam o conceito de inserção profissional entendida como um período de socialização e de construção identitária. 


\section{OPÇÕES METODOLÓGICAS NO ESTUDO DAS TRAJECTÓRIAS OBJECTIVAS E SUBJECTIVAS DE TRANSIÇÃO}

As opções metodológicas são indissociáveis do processo de construção do objecto teórico. A discussão teórica apresenta a transição como um processo multiforme e aberto, com fronteiras de "geometria variável”, tornando-se necessário perceber a complexidade da sua dinâmica e a sua temporalidade. É fundamental a aproximação biográfica no estudo dos percursos, particularmente a perspectiva do curso de vida, que permite realizar um estudo longitudinal capaz de salientar a heterogeneidade dos percursos. Elege-se a dimensão simbólica, a "face escondida da inserção", porque o conceito do qual se parte "indica a ideia de passagem, de um espaço intermédio que tem uma certa duração" e que sofre a influência de "situaçóes anteriores e que pré-figura situações futuras” (ROSE, 1984, p. 50). Além de focalizar as actuais transiçôes entre a escola/formação profissional/mundo do trabalho, elege-se o período de frequência da escola que lhe está a montante, o percurso no mundo do trabalho e o futuro projectado de inserção profissional, a jusante.

No estudo do processo de transição deve reconhecer-se a importância e influência de outros acontecimentos na vida dos jovens que, como mostra Galland (1997), remetem a outras passagens do processo de entrada na vida adulta: a passagem da família de origem à família constituída. $\mathrm{Na}$ análise da transição, não se deve também deixar de considerar as modalidades de gestáo da força de trabalho, postas em prática pelas instituiçóes empregadoras, bem como as políticas estatais nos domínios do emprego e formação, como sugerem Rose (1996) e Vernières (1997). Contudo, deve-se introduzir na análise os elementos subjectivos, relacionados ao significado pessoal do trabalho/emprego para o indivíduo, e à construção e concretização de um projecto de vida e de uma identidade social e profissional.

Os contributos dos autores que propóem critérios objectivos e subjectivos para delimitar os momentos de início e fim do processo de transição foram mobilizados neste estudo, pois é cada vez mais difícil determiná-los, a partir de critérios meramente objectivos. Considera-se importante estudar o processo e as passagens entre o estado de partida 
e o de destino, mas articulando dois aspectos essenciais do processo biográfico: a trajectória objectiva e a trajectória subjectiva.

A trajectória objectiva é definida como a sequência das posiçóes sociais ocupadas no período de transição e durante a vida, medida por categorias estatísticas e condensada numa tendência geral de mobilidade social ascendente, descendente ou estável. É olhada como uma "sequência de posiçôes objectivas" nos campos da educação, formação, do trabalho ou emprego e em outros contextos sociais de vida, identificando-as e definindo-as pelo estatuto jurídico dos empregos e pelas categorias "oficiais" de estudante, activo empregado, activo desempregado, estagiário, bolseiro etc., dando-se importância às categorias institucionais. A proposta é começar por identificar a sucessão de posiçóes, caracterizando a primeira inserção quanto ao tempo de procura do primeiro emprego, ao vínculo contratual, ao sector de actividade e tipo de empresa, à remuneração, à profissão exercida e à sua relação com a área de formação. Em seguida, é necessário analisar as trajectórias de transição tendo em conta a mobilidade de emprego, a mobilidade socioprofissional, o vínculo contratual e o salário, isto é, as posiçóes ocupadas no mercado de trabalho. Por último, deve proceder-se à construção de uma tipologia de percursos-tipo de transição, tendo como indicadores-chave o vínculo jurídico dos empregos, o tempo de procura do primeiro emprego, a duraçáo e manutenção de outros empregos, a categoria a que pertence, a frequência e intensidade do desemprego etc.

Para o estudo das trajectórias objectivas, propóe-se a abordagem extensiva e quantitativa, que tem por objectivo analisar a transição como passagem de um estado inicial a um estado final. Sugere-se a recolha de dados através de questionários que permitem conhecer os percursos estatutários, remetendo para o encadeamento dos episódios e sublinhando as rupturas sucessivas, as mudanças de estatuto (estudante/ trabalhador, inactivo/activo, jovem/adulto), as posiçóes ocupadas, de modo a enumerar os acontecimentos, os lugares, os actores, as sequências e a datação dos diversos períodos.

No que diz respeito às trajectórias subjectivas da transição, os jovens são a parte activa. Além do acesso ao emprego, que circunscreve o estádio final, devem considerar-se as representações dos jovens: a satisfação em relação ao trabalho, o sentido do trabalho gerado pelas condiçóes 
de trabalho, a adequação formação/emprego, etc. Trata-se de ter em conta o que "motiva as trajectórias de inserção" (DRANCOURT; BERGER, 1995), de "elucidar qualitativamente as lógicas das trajectórias", de dar centralidade às "racionalidades subjectivas", de "compreender as representações e as vivências” (DEMAZIĖRE; DUBAR, 1994, 1997). Quando se elege o estudo das trajectórias subjectivas, “o que é visado é a forma simbólica (e primeiro linguística) pela qual eles se contam, argumentam e explicam" (DUBAR; DEMAZIÈRE, 1997). A trajectória subjectiva, que remete às interpretaçóes e para os sentidos atribuídos pelos jovens aos seus percursos e para onde eles radicam, pode ser expressa em diversos relatos biográficos, por meio de categorias inerentes que remetem para "mundos sociais" e condensável em formas identitárias heterogéneas.

Destaca-se a abordagem de Dubar (1992, 1994, 2000) que considera a construção identitária resultado da articulação de dois processos heterogéneos: a transacção "biográfica" e a transacção "relacional". A transacção biográfica remete à identidade para si, fruto de um percurso subjectivo e temporalmente situado, e que consiste em compreender as categorias utilizadas pelos jovens para se definirem, as diversas maneiras pelas quais tentam dar conta das suas trajectórias (escolares, de formação, profissionais, familiares) por meio de uma "história", justificando a sua posição num dado momento e antecipando os seus possíveis futuros em continuidade ou em ruptura com um passado reconstruído. A transacçáo "relacional" se refere à identidade relacional para o outro, que apresenta a questão do reconhecimento ou não pelo outro nos diversos contextos institucionais percorridos e remete às categorias utilizadas para identificar os jovens num dado espaço social, às suas inscriçóes socioprofissionais e à forma como se reveem numa identidade atribuída. É necessário identificar a dupla transacção como expressão da negociação entre a identidade para si e a identidade para o outro, de formas identitárias, social e individualmente construídas.

Para apreender as trajectórias subjectivas é necessário fazer entrevistas biográficas sobre o plano da transição, para obter as narrativas que devem ser examinadas por uma análise estrutural (DEMAZIÈRE; DUBAR, 1997), fazendo-se um exercício de desconstrução e reconstrução, à procura dos seus sentidos e da sua estrutura. $\mathrm{O}$ inquérito permite 
conhecer a sucessão das situaçóes ocupadas por cada um dos jovens em diferentes esferas da sua vida ao longo do tempo de transição; a entrevista, uma peça fundamental da construção dos percursos, permite compreender a história das diversas configuraçóes sucessivas que estrutura a articulação entre essas esferas.

As formas temporais organizam as narrativas de transição e remetem a uma ordem temporal que extravasa o tempo cronológico. Deve atender-se às temporalidades biográficas e às formas de causalidade que acentuam a importância do passado e do processo de transição como tempo de experiências vivenciadas e como tempo de projecção do futuro. Trata-se de conhecer as "trajectórias subjectivas", associadas a formas de temporalidades (CONINCK; GODARD, 1990), que são decifráveis a partir das maneiras de dizer os acontecimentos biográficos (LECLERQ-OLIVE, 2002; DUBAR; DEMAZIÈRE, 1997).

A trajectória subjectiva é a relação do jovem com a sua biografia tal como ela é exprimida na narrativa de vida, isto é, a maneira como o jovem justifica a sua visão de futuro, reconstrói seu passado, mas também pela leitura que faz das oportunidades da sua situação presente (DUBAR; DEMAZIÈRE, 1994). Os jovens colocam a sua vida em intriga através de formas argumentativas pelas quais se esforçam para justificar o seu percurso anterior, para definir a sua situação presente e para falar dos seus futuros possíveis (DUBAR; DEMAZIÈRE, 1997). Ao colocarem a vida em intriga, os jovens expressam a atribuiçáo de sentido sobre os seus percursos de transição, constroem a sua coerência e perspectivam o seu desenlace.

\section{NOTAS CONCLUSIVAS}

O percurso teórico-metodológico aqui apresentado permite considerar a transição da escola ao mundo do trabalho como um processo no qual estão implicados vários elementos constitutivos. Além de acontecimentos como a saída da escola e a entrada no mundo do trabalho, deve-se ter em conta os acontecimentos da esfera familiar, presentes na trajectória de vida dos jovens e que com eles se entrecruzam no tempo da transição. Se não se pode deixar de considerar as medidas de política 
de emprego e de formação implementadas pelo Estado e as modalidades de gestão da força de trabalho nas instituiçóes empregadoras, realçando o peso das estruturas sociais sobre os processos de transição, não se pode deixar de atender aos elementos subjectivos que enfatizam a relação com o trabalho e o sentido atribuído pelos jovens às experiências de transição e à trajectória de vida.

Além da identificação dos critérios que marcam o início e o fim do processo, a transiçáo deve ser considerada essencialmente um período de socialização e de construção identitária que articula a "transacção interna" e a "transacção externa". Estudar o processo de transição entre a saída da escola e a entrada num emprego, que corresponda às aspiraçóes e expectativas dos jovens, obriga a articular o conhecimento da trajectória objectiva com o da trajectória subjectiva: à sequência das posiçôes sociais ocupadas durante o período de transição obtida pelos questionários, deve-se juntar as interpretações e os sentidos atribuídos pelos jovens aos percursos e que estáo expressos nas suas narrativas de transição.

\section{REFERÊNCIAS}

ALVES, M. A inserção profissional de diplomados de ensino superior numa perspectiva educativa: o caso da faculdade de ciências e tecnologia. 2003. Tese (doutoramento) - Faculdade de Ciências e Tecnologia, Universidade de Lisboa, Lisboa, 2003.

ALVES, N. Inserção profissional e formas identitárias: percursos dos licenciados da Universidade de Lisboa. 2007. Tese (doutoramento) - Faculdade de Psicologia e Ciências da Educaçáo, Universidade de Lisboa, Lisboa, 2007.

CHARLOT, B.; GLASMAN, D. (Org.). Les jeunes, l'insertion, l'emploi. Paris: PUF, 1998.

CONING, F. GODARD F. Les formes temporelles de la causalit. Revue Française de Sociologie, Paris, v. 1, n. 31, 1990.

DEMAZIÈRE, D.; DUBAR, C. Analyser les entretiens biographiques: l'exemple de récits d'insertion. Paris: Nathan, 1997. 
DEMAZIÈRE, D.; DUBAR, C (Eds.). l'insertion professionnelle des jeunes de bas niveau scolaire: trajectoires biographiques et contextes structurels. Marseille: Céreq, jan. 1994. 133p. [Documents, Série Synthèse n. 91].

DRANCOURT, C.; BERGER, L. Que sais-je?: l' insertion des jeunes en France. Paris: PUF, 1995.

DUBAR, C. Formes Identitaires et socialisation professionnelles. Revue Française de Sociologie, Paris, n. 33, 1992.

DUBAR, C. L'insertion comme articulation temporelle du biographique et du structurel. Revue Française de Sociologie, Paris, n. 34, p. 283-291, 1994.

DUBAR, C. Réflexions sociologiques sur la notion d'insertion. In: CHARLOT, B.; GLASMAN, D. (Org.). Les jeunes, l'insertion, l'emploi. Paris: PUF, 1998. p. 29-36.

DUBAR, C. Trajectoires professionnelles, formes identitaires et mondialisation. In: Congrés latino-américain de Sociologie du Travail. Anais... Buenos-Ayrès: 2000 .

GALLAND, O. Formes et transformations de l'entrée dans la vie adulte. Sociologie du Travail, Paris, n. 1-85, p. 32-52, 1985.

GALLAND, O. Les jeunes. Paris: La Découverte, 1991.

GALLAND, O. Sociologie de la jeunesse. Paris: Armand Colin, 1997.

LECLERC-OLIVE, M. Temporalités biographiques: lignes et noeuds. Temporalistes, Paris, n. 44, Sept. 2002.

MARQUES, A.; ALVES, M. (Org.) Inserção profissional de graduados em Portugal: (re)configuraçôes teóricas e empíricas. Famalicão: Ediçôes Húmus, 2010.

PAIS, J. Ganchos, tachos e biscates: jovens, trabalho e futuro. Porto: Ambar, 2001.

ROSE, J. L'organisation des transitions professionnelles entre socialisation, mobilisation et recomposition des rapports de travail et d'emploi. Sociologie $d u$ Travail, Paris, v. 1, n. 38, p. 63-79, 1996.

ROSE, J. En quête d'emploi: formation, chômage, emploi. Paris: Economica, 1984.

TROTTIER, C.; LAFORCE, L.; CLOUTIER, R. Les représentations de l'insertion professionnelle chez les diplômés de l'université. In: CHARLOT, B.; GLASMAN, G. (Org.). Les jeunes, l'insertion, l'emploi. Paris: PUF, 1998. p. 390-341. 
VERNIÈRES, M. La notion d'insertion professionnelle. In: VERNIÈRES, M. (Org.). Linsertion professionnelle: analyses et débates. Paris: Economica, 1997. p. 9-22.

VERNIÈRES, M. Formation emploi, enjeu économique et social. Paris: Cujas, 1993.

VINCENS, J. Problematique generale de l'insertion professionnelle: l'insertion professionnelle des jeunes á la sortie des études postsecondaires. Louvain: Institut de Sciences du Travail, Université Catholique, 1981.

VINCENS, J. L'insertion professionnelle des jeunes: a la recherché d'une définition conventionnelle. Formation-Emploi, Paris, n. 60, p. 21-36, oct., 1997.

Recebido em 10 de agosto de 2014.

Aprovado em 10 de novembro de 2014. 